\title{
CMR demonstration of multiple morphological phenotypes in Anderson-Fabry disease
}

\author{
Djeven P Deva ${ }^{1 *}$, Kate Hanneman ${ }^{3}$, Qin Li ${ }^{2}$, Paaladinesh Thavendiranathan ${ }^{2}$, Chantal Morel ${ }^{4}$, Robert M Iwanochko ${ }^{5}$, \\ Andrew Crean ${ }^{2}$
}

From 18th Annual SCMR Scientific Sessions

Nice, France. 4-7 February 2015

\section{Background}

We conducted a review of cardiovascular magnetic resonance studies performed in patients with Anderson-Fabry disease (AFD) at our institution aiming to describe the spectrum of imaging findings in this rare disease.

\section{Methods}

All patients with confirmed AFD who had cardiac MRI at our center were included. Short-axis steady state free precession cines and segmented inversion recovery late gadolinium enhancement (LGE) images were acquired using standard parameters. Offline analysis was performed for LV volumes and maximum end-diastolic wall thickness (EDWTmax). Patients were categorized into 4 groups: 1 ) no wall thickening (EDWT $\leq 12 \mathrm{~mm}$ ); 2) concentric hypertrophy (EDWTmax $>12 \mathrm{~mm}$ with septal to lateral wall thickness ratio $<1.3$ ); 3 ) asymmetric hypertrophy (EDWTmax $>12 \mathrm{~mm}$ with septal to lateral wall thickness ratio $\geq 1.3$ ); and 4) apical hypertrophy. LGE was quantified using a semi-automated technique with thresholds of 2SD, 4SD and 6SD. Charts were reviewed for clinical information.

\section{Results}

Forty-one patients were included ( $53.6 \%$ male, $n=22)$, median age 45.3 years (range 22.3-68.1). Morphological MR findings are summarized in Table 1 . Males were more likely to have increased LV wall thickness and LV mass. The 4-SD threshold for LGE demonstrated the best agreement with manual threshold quantification $(k=0.62) .6$-SD and 2-SD demonstrated lower agreement with manual threshold quantification $k=0.55$ and $k=0.05$ respectively.
Just over two thirds of patients had late gadolinium enhancement (LGE), but only half of these had typical lateral wall mid-myocardial scar. Only a quarter of patients had both concentric wall thickening and typical lateral wall scar. Only 11 of 25 patients with wall thickening had elevated LVMI. There was significantly more myocardial scar (as a percentage of total myocardium) in patients with elevated LVMI $(n=10,10.97 \%$, IQR 7.57-17.43\%) than in patients with normal LVMI $(\mathrm{n}=19$, $1.87 \%$, IQR $1.15-4.37 \%, \mathrm{p}<0.001$ ), and significantly more scar in patients with wall thickening $(\mathrm{n}=21,7.1 \%$, IQR 2.35-11.71\%) than those without wall thickening $(\mathrm{n}=8$, $1.19 \%$, IQR $0.83-2.23 \%, \mathrm{p}=0.003)$. Patients with elevated LVMI had higher incidence of arrhythmia (atrial fibrillation \& ventricular tachycardia[VT]) than those without elevated LVMI (8/13 vs. $3 / 28, \mathrm{p}=0.001)$. Patients with elevated LVMI had higher incidence of VT than those without elevated LVMI (4/13 vs. $1 / 28, \mathrm{p}=0.028)$.

\section{Conclusions}

Concentric thickening and lateral wall mid-myocardial scar are the most common manifestations of AFD, but the spectrum includes cases identical to apical and asymmetric septal hypertrophy subtypes of hypertrophic cardiomyopathy.

\section{Funding}

None.

\section{Authors' details}

${ }^{1}$ Medical Imaging, St Michael's Hospital, Toronto, ON, Canada. ${ }^{2}$ Cardiology, Toronto General Hospital, Toronto, ON, Canada. ${ }^{3}$ Medical Imaging, Toronto General Hospital, Toronto, ON, Canada. ${ }^{4}$ Fred A. Litwin Family Centre in Genetic Medicine, University Health Network, Toronto, ON, Canada.

${ }^{5}$ Cardiology, Toronto Western Hospital, Toronto, ON, Canada. 
Table 1 Cardiovascular magnetic resonance findings in Anderson-Fabry disease

\begin{tabular}{|c|c|c|c|}
\hline & Males $(n=22)$ & $\begin{array}{c}\text { Females } \\
(n=19)\end{array}$ & $\begin{array}{c}\mathrm{p}- \\
\text { value }\end{array}$ \\
\hline Age (years) & $47.4(36.5-55.5)$ & $\begin{array}{c}44.9(34.9- \\
60.8)\end{array}$ & 0.896 \\
\hline Extracardiac involvement & $21(95.5 \%)$ & $15(78.9 \%)$ & 0.164 \\
\hline Prior enzyme replacement therapy & $17(77.3 \%)$ & $11(57.9 \%)$ & 0.313 \\
\hline EDWTmax (mm) & $14.6(13.2-17.2)$ & $11.6(8.9-13.5)$ & 0.013 \\
\hline No wall thickening & $4(18.2 \%)$ & $12(63.2 \%)$ & 0.005 \\
\hline Concentric hypertrophy & $14(63.6 \%)$ & $5(26.3 \%)$ & 0.027 \\
\hline Asymmetric septal hypertrophy & $3(13.6 \%)$ & $1(5.3 \%)$ & 0.610 \\
\hline Apical hypertrophy & $1(4.5 \%)$ & $1(5.3 \%)$ & 1.000 \\
\hline LV ejection fraction (\%) & $58.3(54.2-63.0)$ & $\begin{array}{c}60.4(57.3- \\
65.6)\end{array}$ & 0.200 \\
\hline LV end diastolic volume index (ml/m2) & $\begin{array}{c}92.8(72.1- \\
111.3)\end{array}$ & $\begin{array}{c}83.3(76.2- \\
92.0)\end{array}$ & 0.151 \\
\hline LV mass index (g/m2) & $78.0(64.8-94.7)$ & $\begin{array}{c}56.7(51.5- \\
63.0)\end{array}$ & 0.001 \\
\hline Elevated LV mass index & $9(40.9 \%)$ & $4(21.1 \%)$ & 0.200 \\
\hline Myocardial scar & $16(72.7 \%)$ & $13(68.4 \%)$ & 1.000 \\
\hline Typical midwall lateral wall scar & $6(27.3 \%)$ & $8(42.1 \%)$ & 0.346 \\
\hline Patients with concentric hypertrophy and typical midwall lateral wall scar & $5(22.7 \%)$ & $4(21.1 \%)$ & 1.000 \\
\hline $\begin{array}{l}\text { Patients with concentric hypertrophy and typical midwall lateral wall scar } \\
\text { Scar as percentage of total myocardium at 4SD calculated from } 16 \text { males and } 13 \text { females with myocardial } \\
\text { scar (\%) }\end{array}$ & $4.9(2.0-10.8)$ & $1.9(1.2-10.2)$ & 0.381 \\
\hline
\end{tabular}

Age is presented as median (range). All other continuous variables were compared with a Mann-Whitney Rank Sum test and presented as median (interquartile range). Categorical variables were compared with a Fisher test.

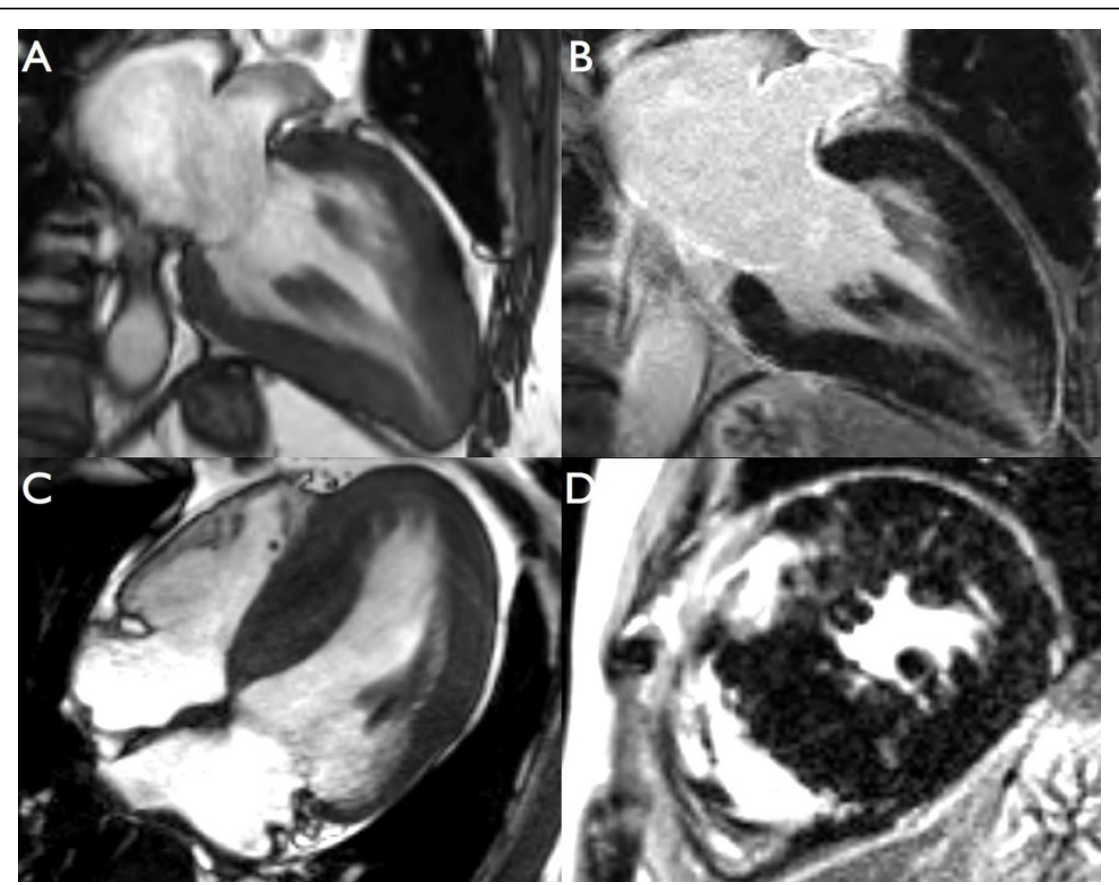

Figure 1 A-B. 63 year old female with Anderson-Fabry Disease on enzyme replacement therapy and a history of ventricular tachycardia. CMR reveals an apical pattern of hypertrophy and apical scar. C-D. 58 year old male with Anderson-Fabry Disease on enzyme replacement therapy. CMR reveals reverse septal curvature subtype of asymmetric septal hypertrophy and predominantly hinge point scar 
Submit your next manuscript to BioMed Central and take full advantage of:

- Convenient online submission

- Thorough peer review

- No space constraints or color figure charges

- Immediate publication on acceptance

- Inclusion in PubMed, CAS, Scopus and Google Scholar

- Research which is freely available for redistribution 